\title{
Aportaciones especiales de derecho y equidad en las vicisitudes del concurso*
}

\author{
Manuel María Zorrilla Ruiz \\ Catedrático Emérito de la Universidad de Deusto \\ Ex Presidente del Tribunal Superior de Justicia del País Vasco \\ Presidente de la Asociación de Jueces y Magistrados Jubilados de España
}

Recibido: 21.11.07

Aceptado: 22.10 .08

\begin{abstract}
Resumen: El vigente procedimiento concursal puede beneficiarse de las aportaciones consistentes en dictámenes jurídicos externos y acciones de mediación equitativa. Los primeros conciernen a la unidad de las empresas ocultas bajo apariencias de pluralidad, a la noción de persona especialmente relacionada con el deudor, a la designación de delegados del órgano de administración, a la atribución de competencias específicas, a la determinación del nivel de diligencia de los administradores y a las expresiones de la justa causa. La segunda destaca la importancia del esfuerzo de los mediadores para garantizar la viabilidad futura de la empresa y conservar el mejor de los niveles posibles de empleo. La continuidad de las actividades productivas, en vez de la venta forzosa de la empresa o de sus elementos, resalta la naturaleza de derecho fundamental que adquiere la libertad de iniciativa económica.
\end{abstract}

Palabras clave: Concurso. Informes jurídicos externos. Acción mediadora. Transmisión de empresa. Libertad económica.

Abstract: The prevailing procedure of insolvency admits the benefits consisting in the reception of external opinions and the actions of an equitable mediation. The first concerns to the unity of the enterprises hidden under the appearence of plurality, to the notion of people specially related with the debtor, to the designation of the delegates of the administration, to the assign of specific attributions, to the level of the duty diligence and to the idea of juste cause. The second shows the importance of the task developped by the mediators to assure the future viability of the enterprise and the best level of occupation. The continuity of the industrial activities, instead of the unavoidable auction of the enterprise or its elements, shows clearly the nature of fundamental rigth accquired by the economic freedom.

Key words: Insolvency. External opinions of law. Mediation. Transmission of the enterprise. Economic freedom.

* Este trabajo forma parte de la contribución del autor al cuestionario del curso que, sobre Metodología de la Administración Concursal, organiza, en el $1{ }^{\mathrm{er}}$ semestre de 2008, el CGPJ (Consejo General del Poder Judicial). 
Sumario: 1. Sucesión de actitudes ante la efectividad del Derecho y modernidad del llamamiento al depósito de las normas del orden natural de la equidad y a los modos extrajudiciales de composición de conflictos.-2. Operaciones de Derecho y emisión de pareceres extrajudiciales en circunstancias notables e interesantes del concurso.-3. Supuestos aconsejables de mediación equitativa que pueden darse en momentos notables del proceso concursal.- 4. Otros casos de mediación cualificada en las operaciones del concurso.- - 5. Utilidad de las formas de mediación equitativa en los casos de enajenación forzosa del todo empresarial o de unidades productivas autónomas. - 6 . Conclusiones acordes con los razonamientos que preceden.

\section{Sucesión de actitudes ante la efectividad del Derecho y modernidad del llamamiento al depósito de las normas del orden natural de la equi- dad y a los modos extrajudiciales de composición de conflictos}

Vale afirmar, como premisa de estas reflexiones, que la emisión de dictámenes especializados o suplementarios -al margen de las actuaciones de un proceso concreto- obedece a la necesidad de acelerar la pacificación jurídica de las contiendas, como aquí ocurre con ciertos episodios del concurso, y cooperar a que el mundo del Derecho se mire en el espejo de un universo equilibrado, donde la razonabilidad -ecuánime y serena- triunfe sobre las adversidades antagónicas. El llamamiento a los modos de composición que encierran la conciliación, la mediación y el arbitraje, se explica por el común afán de prestigiar y difundir unas soluciones de equidad cuya intensa demanda social acrecienta la serie de sus justificaciones.

El tratamiento de los problemas jurídicos requiere hoy día -acaso más que nunca- la toma en consideración de la equidad, acogiendo las soluciones arregladas a la justicia material, a la sugestión del buen sentido, a la preponderancia del dictamen de la recta razón y a la explotación del depósito de las normas del orden natural. No es ésta una idea aparatosamente nueva, sino conscientemente compartida por cuantos forman la comunidad de juristas y asumen igual inclinación.

Los juristas y los historiadores especializados han presenciado las predilecciones que -a la hora de elegir el mejor de los Derechos deseables- acusaban alternativas monótonas y aleccionadas por sus consecutivas experiencias. A la apuesta por soluciones equitativas individualizadas sucedió la que propiciaba un Derecho general en el espacio, protector de los intereses peculiares de un ámbito geográfico de soberanía, y en el tiempo, dadas sus pretensiones de alcanzar una eficacia duradera. La elección -técnicamente irreprochable y ungida por un espíritu de naturalidad y de progreso- no ha saciado el hambre y la sed de justicia de los pobladores de la familia humana. Por aquello de ser lo mejor enemigo de lo bueno, los clamores de la restauración de la equidad resucitan, apremian y se incorporan a los signos de 
los tiempos. Ni los atestados depósitos del Derecho común de las recepciones, ni la autenticidad del yusnaturalismo realista que aportó los materiales básicos de la obra codificadora, ni la evolución de ésta en sí misma, ni las relativizadas ambiciones del Derecho común europeo -por citar, de pasada, los hitos más visibles- han fraguado un estilo de justicia que acoja las demandas de un Derecho equitativo, saludable y añorado por cuantos no pueden celebrar aún las excelencias de su aplicación ni beneficiarse de sus efectos admirables.

La propuesta que, en el último tercio del siglo pasado, defendió la recepción modernizante de un Derecho llamado mundial, más bien que universal, auguraba -con la ingenuidad de los estudiosos de laboratorio- que la futura acción los poderes públicos garantizaría la solidez de su establecimiento, aumentaría sus elementos de justicia, implantaría un bien común universal y frenaría los excesos de los adelantos industriales y tecnológicos. La Historia -plagada de sucesos y exenta de razones- ha obrado como las contrarrevoluciones que devoran las adquisiciones más caras de las revoluciones más tenues. Las agresiones de la globalización y los éxitos -un tanto deplorables- de su elevación a la segunda potencia han anulado la energía de los poderes públicos y propiciado estados de injusticia costosos de empeorar. El Derecho -intencionalmente traicionado o negligentemente defraudado por la tibieza y/o la holganza de sus promotores naturales- sólo tiene a mano, para luchar desventajosamente contra esos modos de vivir injustos, las actuaciones individualizadas que, contrayendo un compromiso de equidad retador y heroico, procuren la dosis de efectividad moral que, por doquier, se echa de menos cada día.

El renacimiento de la pasión equitativa se debe a que el constituyente ha recreado un ordenamiento jurídico cuyas normas no sólo han de ser formalmente válidas, "sino también materialmente justas. El art. 3.2 C.c. (Código Civil español de 24 de junio de 1889, reformado, en este punto por la Ley de 31 de mayo de 1974) rehusó apelar a cualquier término escolar de la nomenclatura filosófica y prefirió adherirse a la invocación nominal de la equidad. Las cosas han cambiado desde que la figura del Estado compuesto de las Autonomías sucedió al régimen paternalista autoritario -llamado así por los estudiosos de la Ciencia Política- que le precedió de inmediato. La concepción actual de la equidad, a la luz de los arts. 1.1 y 9.2 CE (Constitución española de 27 de diciembre de 1978), ha remozado su etiqueta y comprensión minimalistas de remedio exclusivamente destinado a limar las asperezas de la ley. La equidad equivale, hoy por hoy, al óptimo de justicia material que compendia la igualdad de condiciones y de oportunidades, para insistir en su persecución, y la libertad bien orientada, para encontrar los mejores modos de explotar su generoso ofrecimiento.

La aptitud de ejercicio de las variantes de composición extrajudicial se gana por acción, por reacción o por las experiencias debidas a las expresiones -ejemplares, oportunas y didácticas- de cualquiera de ellos. Cuantos han 
servido funciones jurisdiccionales durante un tiempo suficientemente pedagógico para sentar criterios válidos y sólidos, guardan buena memoria de aquellas ocasiones -las menos- en que pudieron usar de la equidad excepcionalmente autorizada por el legislador, y de las más, en que, pese a lo tentador y convincente de las soluciones equitativas atisbadas, sus ilusiones tropezaron con el deber de someterse únicamente al imperio de la ley que cegaba otras vías de acceso a los bienes de la justicia material. Las experiencias que así se han vivido abarcan los encuentros con la equidad específicamente autorizada y los desencuentros con la interdicción de utilizarla provechosamente.

Los modos de composición aptos para rehabilitar -severa y perdurablemente- la equidad han sido, de menor a mayor, la conciliación, la mediación y el arbitraje. Al cobijar sus diferencias específicas bajo el género próximo de equivalentes jurisdiccionales o sustitutivos procesales, no se cede a una predilección estética y, en cambio, se da paso a una certera precisión dogmática. Si el primero se muestra más sencillo, los demás endurecen y complican la intervención de los mediadores y los árbitros.

La conciliación presupone la evidencia y los inconvenientes de un conflicto en que -asistidas por el órgano conciliador- las partes desempeñan la labor capital de reducir las diferencias que turban sus confrontaciones e inmovilizan sus ademanes respectivos. La acción de los conciliadores tiene lo suyo de mayéutica, porque promueve los acercamientos latentes en los entendimientos y las voluntades -obnubilados o indecisos hasta entoncesde los interesados. La técnica de la conciliación insinúa-sugiriendo tan sólo y absteniéndose de dictar soluciones terminantes, exclusivas y excluyenteslos cambios de rumbo convenientes a las iniciativas o actitudes de las partes, endereza o clausura los caminos erróneamente recorridos en el curso de la conciliación y disuade de las razones descabelladas o de los extravíos aberrantes que en esos trances suelen abundar. Respetando el poder de decisión de las partes, se les brindan ayudas que influyen en sus convencimientos, les invitan a superar lo rudimentario o elemental de sus discursos y fomentan un lúcido progreso hacia los puntos de encuentro que intentan aunar los objetivos pacificadores.

La mediación se señala por una intervención singularmente activa y dinámica del órgano unipersonal o colegiado que la tiene a su cargo. La mediación absoluta existe cuando, conociendo el alcance y contenido de las diversidades dignas de salvarse, el mediador adelanta el todo de la solución o dispone-gradual y cautamente-las piezas del discurso que transmite a las partes para escrutar su fuerza persuasiva y obtener su adhesión, si es del caso. Los interesados expresan su aceptación o su disenso -íntegros o condicionados- $y$, en vista de las posturas adoptadas y de su potencial contradictorio, el mediador propone remodelaciones sucesivas que, seduciendo y catequizando a las partes para obtener su consentimiento, producen el efecto esperado del modo de composición elegido. Hay mediación relativa si -al 
aportarse soluciones que, aunque conceden o transigen, no coinciden pacíficamente- el mediador aprovecha, algo así como a cuenta, los anticipos que cooperan al buen fin de su interposición y completa un trabajo similar al de la mediación absoluta. La mediación elástica se distingue por su reversibilidad, pues, en el curso de su avance, puede volverse sobre anteriores acuerdos interlocutorios que se sustituyen o enmiendan para adecuar los efectos equitativos del equivalente jurisdiccional a la suma de las conformidades conseguidas con la intervención del mediador.

El arbitraje de equidad concentra en el papel y la gestión de los árbitros las funciones de legislar y resolver. El ejercicio de la cuasilegislación arbitral -en parte análoga y en parte diferente de la figura de la ley de caso úni$c o-$ requiere que el árbitro, inmerso en el depósito del orden natural de la equidad, extraiga de su interioridad insondable, la sustancia de una pauta irrepetible e individualizada que modela con tacto y consciencia de las dificultades inherentes al enunciado -veraz y no sofístico- de sus proposiciones normativas. La cuasijurisdicción arbitral subsume en la regla elaborada para dilucidar el caso único -aunque exigente de las visiones ópticas de los legisladores generales- un estado histórico de cosas que no siempre dispone de acomodo exacto en el espacio y en el tiempo. Además de afectar a los hechos cosmológicos, los arbitrajes de equidad conciernen a unas realidades políticas, sociales, internacionales y económicas cuya individualización y prueba son harto fatigosas para desembocar en un resultado equitativo y asegurarlo con visos de perdurabilidad y de mejor fortuna.

\section{Operaciones de Derecho y emisión de pareceres extrajudiciales en cir- cunstancias notables e interesantes del concurso}

Hay vicisitudes o incidencias del concurso que -tanto a causa de su importancia técnico-jurídica como de sus connotaciones económicasdemandan los refuerzos adicionales de la aportación de informes, dictámenes o pareceres exteriores al procedimiento, pero, a no dudarlo, provechosos para la justa suerte de los intereses en juego. Su emisión, lejos de suponer una actividad preventiva o escuetamente teórica, se explica por la profundidad y el arrojo de los razonamientos, a que los temas debatidos obligan, y por el fervor y aun el encono de las tesis que en cada momento se defienden. El Derecho es una disciplina del espíritu que, ante las vacilaciones sometidas a su veredicto, no pone fronteras a las especulaciones -robustecedoras o alternativas- de una determinada solución inscrita en el mundo del valor, sino que excita a la multiplicación y divergencia de esas aventuras. He ahí su diferencia con las ciencias de la naturaleza y con el panorama del mundo del ser. No hay que dar por irreversiblemente buenos -convirtiéndolos en productos intangibles de la dogmática o doctrina fijada- los argumentos que, difundidos y aceptados como razonables, sufren el impacto de otros que les 
revigorizan, con la fortaleza intelectual de sus acertadas ratificaciones, o les inutilizan y desplazan con superior poder de convicción. Carácter del que participan las hipótesis en que, para completar la asistencia jurídica interior del concurso, esas necesidades surgen y exigen atenciones. Acaso estén entre ellas las que a continuación se consideran.

El art. 3.5 LC (Ley Concursal de 9 de julio de 2007) legitima al acreedor para instar la declaración judicial del estado de concurso de varios deudores que, sin estar obligados por el mismo título jurídico, figuran como titulares formales de patrimonios cuya confusión es patente, o, tratándose de personas jurídicas, constituyen un grupo inescindible en virtud de la identidad sustancial de sus miembros y de la unidad con que sus determinaciones se adoptan. Esta variante del llamado alzamiento del velo disipa la oscuridad o la penumbra en que se sume una realidad jurídica de exhumación indispensable para probar lo artificioso de la dispersión denunciada. La legitimación del deudor se desempolva en términos de cognoscibilidad y percepción adecuados a todas las garantías que, según el art. 24.2 CE, forman parte del contenido esencial o núcleo invulnerable del derecho fundamental a la efectiva tutela judicial. Sólo así lucen la veracidad y el encadenamiento de las circunstancias históricas que hacen del interés protegido -mediante la solicitud de declaración del concurso- lo que es y significa, en vez de su contrafigura desorientadora. Se esfuma una apariencia -generalmente fruto de exquisitas operaciones de ingeniería financiera-que, empeñada en cegar los caminos conducentes al fondo de las cosas, opone insalvables obstáculos a la efectividad de un derecho fundamental cuyo reconocimiento, según reza el art. 53.1 CE, goza de eficacia preceptiva directa y vincula a todos los poderes públicos.

De algún crédito goza esta estrategia que, tras cobrarse sus primeras víctimas, cosechó - por obra y gracia de la entonces arrolladora teoría del uso alternativo del Derecho- resonantes victorias en los pagos del Derecho Social. Para esquivar y combatir eficazmente las formas fraudulentas de fraccionamiento o disgregación engañosos de la unidad natural del concurso, hay que realzar el perfil de la figura que, pese a lo proteico y desorientador del disfraz confeccionado para esconder su verdadero rostro, encarna una unidad indivisible de dirección y de riesgo. La rotulación encabeza un capítulo notable de la lucha por el Derecho y conecta con una estadística fenomenológica que -ante la terquedad de los experimentos de ocultación y la suerte de los manejos que los apadrinan- da idea de la dificultad de alzar el velo desplegado sobre una compacidad sepultada, desfigurada e invisible. Para localizar estas operaciones y reprimirlas en nombre del Derecho, se cuenta con definiciones adecuadas a los casos de ocultación que representan. Son definiciones descriptivas que no siempre atajan las escapatorias caracterizadas por la sutileza y densidad del camuflaje que -modernizando las técnicas del Liber fugitivus - renuevan, sin cesar, sus valedores. La unidad de dirección significa que las expresiones del poder de decisión -relativo a la 
organización interior y a las relaciones económicas externas de la persona jurídica- emanan de una voluntad común, no obstante las tretas urdidas para convencer de que, en su lugar, intervienen voluntades autónomas, divididas e independizadas. La unidad de riesgo implica, entre otras muestras de su naturaleza aglutinante, que los patrimonios de las personas jurídicas -acogidas a las limitaciones de las responsabilidades patrimoniales respectivasquedan desposeídas de una garantía que ya no les es propia. Al superarse -en pro de la prevalencia y autenticidad de la justicia material- uno de los privilegios o ventajas de la personalidad jurídica de las sociedades de capitales, la integridad funcional de los elementos de los patrimonios -cuya confusión se sabe, se alega y se demuestra- se ve atrapada por las responsabilidades anejas al ejercicio de una dirección única, desde sus orígenes, más bien que unificada. La verificación de si el supuesto descrito por el art. 3.5 LC -revelador de una legitimación pasiva unitaria e incompatible con las apariencias de pluralidad que se desploman- ha de primar sobre la realidad superficialmente advertida, depende del tacto de las averiguaciones históricas y del tino de las apreciaciones jurídicas que afluyen a esas conclusiones. No es lo mismo la confusión de patrimonios - permeabilidad de personas sociales cuya responsabilidad deja de constreñirse- que las modalidades de tangencia, intercomunicación episódica o coasistencia patrimonial que, al margen de una supuesta confusión, reflejan relaciones de porosidad menos intensa, surgidas también de las vigilias de los virtuosos de la ingeniería financiera. La prueba de que se forma parte del mismo grupo obliga a un análisis inicial de la estructura que confirma lo veraz e inalterable de ese dato o, al contrario, acusa disfunciones y/o fisuras que impiden calificar de grupo a formas -más tenues o descomprometidas- de cooperación o asunción de objetivos comunes que hay que recalificar caso por caso. Una cosa es la identidad sustancial-cuyo adjetivo de omnicomprensión se acepta precipitadamente, pues el concepto no se opone lógicamente al de una cuestionable identidad accidental-que, como título de conglomeración, se predica de los componentes del grupo. Otra, la inmersión de sus miembros en las variantes de afinidad o acercamiento que les relacionan. La unidad de la adopción de decisiones ha de ser permanente -rectius, duradera-y monolítica, excluyéndose las casualidades que, aparentando indisolubilidad o coherencia, se reducen a pactos itinerantes o convenios de vida muy corta. Los conceptos jurídicos indeterminados a que estas consideraciones se refieren no se delimitan sin preconstituir escrupulosamente las razones determinantes de la existencia y juridicidad de los aspectos que individualizan la especie de legitimación analizada. El velo, que ha de levantarse, no suele ser de ligereza tal que haga cómoda su remoción, y sí de una espesura inteligente que entorpece muy mucho la operación de su retiro.

El contenido incompleto de estos juicios o las insuficiencias -de hecho y de derecho- que presenta la legitimación pasiva de los deudores del concurso -superpuestos a la unidad de dirección y de riesgo- revela un defecto 
exigente de que, como reza el art. 13.2 LC, se recabe del solicitante de la declaración de aquél una justificación motivada y plausible o una ampliación de los extremos que desembrollan el artificio advertido por el art. 3.5 LC. Aspecto de entidad bastante para explicar la utilidad de pareceres jurídicos externos que iluminen el planteamiento y la salida o salidas de tan embarazoso problema. Demostrar, en un plazo harto breve, la identidad del deudor encubierto, conduce a dos alternativas. Cuando el peticionario está en condiciones de cumplir, sin mayores esfuerzos, esa carga antes de formularse la solicitud, ha de arrostrar las consecuencias de haber omitido la diligencia que, a la sazón, pudo y debió prestar para desvanecer las ocultaciones o las situaciones equívocas. Otra conclusión se seguiría si, a la luz del art. 24.1 $\mathrm{CE}$, la instrumentación de un razonamiento suplementario solvente no quedaba al alcance de la diligencia que, cuando se instó la declaración de concurso, tenía que desplegar el acreedor según las circunstancias de las personas, del tiempo y del lugar. El solicitante permanece indefenso -con merma del principio procesal de contradicción o audiencia bilateral- si no goza de un plazo atemperado al cuanto de información y raciocinio que requiere el cabal cumplimiento de la carga exigida.

$\mathrm{El}$ art. 28.3 LC cita uno de los filtros que -para depurar la objetividad de los miembros de la administración concursal- reclaman operaciones de precisión suplementaria. La noción de persona especialmente relacionada con el concursado - a la que se veda formar parte de esa administración- confiere al adverbio de modo utilizado una ductilidad conceptual que rebasa la ejemplificación del art. 93 LC. Exige discurrir acerca del alfa y el omega que, cuantitativa y cualitativamente, son el principio y el fin de las variantes de una especialidad de la relación que lo mismo puede ofrecer fisonomías de signo impredecible, que causar la impresión de concurrir en situaciones cuyo análisis termina demostrando - contra lo presumido- que nada tienen de especiales el vínculo o la comunicación que se objetan. ¿Acaso, por proponer un ejemplo atípico, no hay una relación especial -preexistente y ocultaentre el concursado y un tercero que, conociendo actividades inconfesables del primero, le somete a una coacción tácita, indemostrable y permanente?

$\mathrm{El}$ art. 32.1 LC se ocupa de la autorización judicial del nombramiento de auxiliares delegados de la administración concursal y de su designación consiguiente, si así lo exige la complejidad del concurso. Dos nociones de contenido variable confluyen en la labor de esclarecer las dificultades que salen al paso. Una es la de complejidad o dimensión del interés que la norma protege en cantidad y/o calidad. Otra, la de la exigencia que atañe a lo perentorio de la protección. El rostro visible del concurso puede reflejar un cúmulo o densidad de interrogantes que, aun confiriéndole una naturaleza acorde con alguna de ambas condiciones, no adquieren la complejidad de que se hace mención. Según el más plausible de los entendimientos que procuran los elementos interpretativos conjugados por el art. 3.1 C.c., complejidad es tanto como diversidad evidente de problemas -que, aunque arduos de por sí, 
no tienen por qué ser numerosos ni excesivos-e imposibilidad o dificultad extraordinaria de acudir a las visiones más elementales o utilizar las herramientas más accesibles y frecuentes para seleccionarlos, ordenarlos sistemáticamente, reflexionar sobre su magnitud y resolverlos. Si la administración concursal logra aclarar, con los recursos propios y sin demasiados obstáculos, cuestiones que -prematuramente tildadas de complejas- afectan a una parte o al todo del concurso, no media el supuesto indicado y hay sólo una situación artificiosa que se aparta del concepto técnico-jurídico de complejidad. Tras esta consideración, cabe multiplicar las conjeturas sobre el significado del término y los riesgos de la propensión a suscitar falsos problemas, asociando la complejidad a cuestiones secundarias o peripecias del concurso que ni de lejos se confunden con ella. Guardadas las distancias, lo mismo se predica del giro... así lo exija..., pues, aun supuesta la complejidad del concurso, la competencia técnica de los gestores de la administración concursal basta, en ocasiones, para salvar muchos inconvenientes de monta, excluyendo, como casos de complejidad, los que son sólo temas de utilidad o conveniencia. Estos últimos descartan la exigencia - peculiar de un estado de cosas ineludible e insoluble sin el auxilio interesado- o la necesidad de solicitar la autorización judicial para desconcentrar, mediante la intervención de los auxiliares delegados, ciertos cometidos de la administración concursal. He aquí una de las regulaciones que, afinando sus conceptos jurídicos indeterminados, acomoda las cargas del concurso a su grado de accesibilidad o a los reparos de una complejidad que, lejos de prejuzgarse voluntaristamente, debe intelectualizarse con esmero y a la vista de las circunstancias que la determinan. La notabilidad del problema aconseja el auxilio suplementario de pareceres o estudios externos para aligerar esas dificultades.

Según el art. 36.1 LC, la singularidad del cuidado y atención que han de animar-como elemento espiritual o intelectual- la ejecución -como elemento material-de las funciones de los administradores concursales y de los auxiliares delegados, consiste en observar la diligencia de un ordenado administrador y de un representante leal. Trátase de un aspecto conexo con la exigencia de responsabilidad que el art. 36.1 LC asocia a la omisión de la diligencia debida o exigible. Para atender a ello, hace falta canonizar los criterios decisivos que permiten individualizar la diligencia requerida y sancionar sus omisiones. La concepción normativa de la culpabilidad -orillada por el Derecho Privado- proclamó la necesidad de comparar las acciones o abstenciones, objeto de censura, con una regla de conducta construida en abstracto o en concreto. Se pregunta si la dicción legal comulga con semejante orientación o si debe primar el aforismo -pedestre y superado- de que no cabe distinguir allí donde la norma jurídica tampoco tiene a bien entablar distinción. Esta simplicidad pierde peso si se nota que, a la luz del art. 3.1 C.c., la regla del art. 35.1 LC se adueña del espíritu y finalidad -a los que fundamentalmente ha de atenderse- de garantizar una gestión aseada de los intereses del concurso y superar cuantos óbices nacen de sus complicaciones 
técnico-jurídicas o de sus eventos patológicos. En vista de este postulado y acaso de otros no menos relevantes, lo razonable y cuerdo es distinguir. La tesis más condescendiente prefiere apelar a la inducción y, para diseñar el modelo general de administrador, parte de una verificación estadística que -ponderando equitativamente y extrayendo los elementos comunes de la actuación profesional de los servidores de ese oficio- los integra en la regla de conducta merecedora de observarse. Norma resultante de las operaciones de abstracción relativa efectuadas sobre una pluralidad homogénea de comportamientos a los que se aplica el método inductivo. Obediente a una técnica que impera en las relaciones de Derecho Privado y que data de la ya citada concepción normativa de la culpabilidad, adoptada y difundida por los especialistas del Derecho Penal. Ello no excluye que la traza de los intereses del concurso reclame una apreciación más pulcra, pormenorizada y exigente de los deberes de los administradores concursales. Si sus usuales hábitos de atención y cuidado superan a los resultantes de aplicar la norma generada en abstracto, la lealtad, la corrección y la buena fe -de que los arts. 7.1 C.c. y $35.1 \mathrm{LC}$ se ocupan en términos afines- requieren mantener unos niveles -más estrictos- de celo y vigilancia que prohíben volver contra lo continuo y evidente de los propios actos. La norma de comportamiento endurecida se confecciona comparando la actuación presente de los administradores concursales o de los auxiliares delegados con su modo anterior de proceder en situaciones afines y se aplica en la medida que afronta, más enérgicamente, la necesidad de proteger los intereses del concurso. La teoría de la concepción normativa de la culpabilidad dota de un ingrediente de seguridad que, como la regla de comportamiento configurada en su virtud, fulmina los criterios -casuísticos, incoherentes o erráticos- que suelen emplearse para graduar el uso de la debida diligencia. Los rasgos particulares del problema le convierten en oscuro objeto del deseo de informes de adición que suavicen sus perfiles más ásperos, sin limitarse, como frecuentemente ocurre, a reducciones o prejuicios que -atentando contra la dignidad lógica del razonamiento- empobrecen de todo punto su discurso.

El art. 35.2 II LC permite atribuir competencias específicas a uno o varios de los miembros de la administración del concurso. Aun cuando no se exige petición justificada y, en el más llano de los casos, parece aludirse a episodios de distribución o reparto de trabajo, es dable la hipótesis -consecuente, como manda el art. 3.1 C.c., con el elemento interpretativo contextual- de que, ante la naturaleza de esas competencias, la propuesta cursada y la decisión judicial recaída dependan de verificaciones fácticas y de razonamientos jurídicos que condicionan el sentido de las contestaciones procedentes. Habrá que detallar las circunstancias en que se funda la solicitud-adornada de un raciocinio convincente- y señalar si, amén de las novedades históricas invocadas, median razones de Derecho que justifican la importancia de aquella atribución. El desglose propuesto no ha de menoscabar los mínimos definidores del deber de diligencia. No sólo son competencias específi- 
cas las que se siguen de la redistribución indicada, sino también las que -atendiendo a pormenores de la fisonomía del concurso- se innovan justificadamente. Al discurso creador de las competencias específicas incumbe reseñar sus particularidades de ejercicio, prevenir sus actuaciones extralimitadas o abusivas y proveer a las alternativas de su contenido variable. La operación difiere de la -más sencilla- que, según el art. 32.1 LC, consiste en asignar atribuciones a los auxiliares delegados. Una hipótesis en que el soporte de pareceres jurídicos externos no es superabundante, sino recomendable y enriquecedor.

La figura de la justa causa es, por excelencia y tradición, un concepto de dimensiones elásticas acuñado de antiguo para fomentar las operaciones de equidad que -a fin de prevenir los desatinos o peligros de ciertas concreciones- el legislador traslada a una norma jurídica en blanco que colman sus aplicadores o intérpretes. Ha imperado la idea de que, si el último fin último del Derecho reside en consolidar la paz jurídica, la invocación y la aceptación de la justicia de la causa -inspiradoras de actitudes social y moralmente decorosas- valen lo mismo o más que las de muchas normas positivas de altos vuelos. El art. $37 \mathrm{LC}$ prefiere eludir los inconvenientes de las enumeraciones taxativas u otros entorpecimientos que, al frenar los impulsos de la recta razón y el buen sentido, impiden decidir si una determinada situación -individualizada y éticamente censurable- da lugar a la separación del cargo de los administradores concursales o a la revocación del nombramiento de los auxiliares delegados. Una cosa es que la jurisdicción goce de facultades discrecionales para acordar tales medidas y otra -completamente inadmisible- que se le niegue el poder de revisar, con base en argumentos de equidad, los hechos que se dicen constitutivos de la justa causa innominada, amén de las legalmente previstas y cuya bondad no está en tela de juicio.

El juicio de equidad sobre la mediación de justa causa dota de oportunidades para la emisión tempestiva -ayuna de precipitaciones y/o peticiones de principio- de opiniones extrajudiciales o preparatorias. Requiere explotar los yacimientos accesibles y ahondar en los mensajes de un concepto jurídico indeterminado que, pletórico de flexibilidad y oportunidades comprensivas, condena los vicios de la laxitud o el pensamiento débil. Compromete un tanto de razonamiento que, tras la disección de cada caso, concluye si la especie contemplada pertenece o escapa al género ideal de justa causa. El juicio de equidad reta imperiosamente a los juristas que, para su emisión satisfactoria, tienen que conjugar una línea doctrinal de continuidad-intuitiva de si la justa causa existe o brilla por su ausencia- y un principio histórico de progreso, que invade los ambientes en que el Derecho luce y aspira a realizarse. La equidad auspiciada es la justicia sustancial refrendada por la delimitación transparente del ordenamiento jurídico, que ofrece el art. 1.1. CE, y por la cláusula transformadora y social que recoge el art. 9.2 CE. La ventaja asistencial de los pareceres externos se justifica porque el discurso jurídico se expone a inevitables desviaciones cuando - previendo algunos efectos nega- 
tivos de su talante generalizador- el legislador atribuye potestades de arbitrio equitativo a los particulares, si aplican extrajudicialmente la norma jurídica, y a la jurisdicción revisora del uso -adecuado o excesivo- que cabe hacer de esa delegación.

$\mathrm{El}$ art. 42.1 LC grava al deudor con los deberes de cooperación que le exigen colaborar en todo lo necesario o conveniente para el interés del concurso y procurar la información precisa a tales fines. Parece más atinado aludir, desde una perspectiva conceptual, a los intereses de las personas físicas o jurídicas afectadas por las vicisitudes del concurso. Del deudor -requerido al efecto- se esperan las actuaciones consistentes en dar, hacer y abstenerse, sobre los puntos de la contribución reclamada, y en emitir manifestaciones -más frecuentemente de voluntad que de conocimiento- presumiblemente veraces. La cooperación y la información dependen del respeto que, dado el carácter de esas intimaciones, recaba el contenido esencial o núcleo invulnerable de los derechos fundamentales y las libertades públicas a que los arts. 53.1 CE y 7.1 y 2 LOPJ (Ley Orgánica del Poder Judicial de 1 de julio de 1985) cuidan de aludir. También se ha de evitar que las expresiones del derecho a la efectiva tutela judicial -movilizado en pro de los intereses del concurso- erosionen el núcleo intangible de otros derechos concurrentes. La acumulación de las nociones de necesidad o conveniencia suscita, en fin, un problema de exégesis. Ya que la invocación -más laxa- de la conveniencia embebe, de menor a mayor, la de la necesidad que agrava la primera, la doble mención huelga, de no entenderse que el precepto tolera una lectura críptica que, a la luz de su lectura lógica, no es fácilmente imaginable, al menos de momento.

Supuesto que los impropiamente llamados intereses del concurso se defienden con la efectividad de las variantes de convenio y, en su defecto, con los resultados económicos de la liquidación, el art. 43.1 LC prevé la posibilidad de que el órgano de administración solicite de la jurisdicción el auxilio que estime necesario para conservar la integridad patrimonial de la masa activa del concurso. Concepto -el de auxilio necesario- que, sin perjuicio del objetivo a que sus actividades se enderezan, va más allá de las acciones físicas de conservación y se emparenta con otras categorías jurídicamente importantes. Los actos dispositivos o de enajenación modifican cuantitativa o cualitativamente la composición del patrimonio. Los actos de conservación impiden el flujo de los bienes y derechos que, dejando de pertenecer al patrimonio, empobrecen a su titular. Los actos de administración o de gestión -comprimidos por ambas delimitaciones- vienen a ser, por exclusión, los que no traen consigo disposición ni simple conservación de bienes y derechos. Muchas y divergentes opiniones pueden darse para definir tales variantes y graduar sus repercusiones en la protección de un interés primordial del concurso - a saber, la garantía de la integridad patrimonial de la masa activa- que se beneficia del esmero conveniente a su naturaleza y a la evitación de cualesquiera deterioros que la menoscaben. El repertorio de 
los auxilios necesarios comprende valoraciones económicas y jurídicas que, aquilatando los intereses del concurso, fijan los máximos y mínimos de la urgencia invocada a la sazón. Conviene sumar a estos análisis, una lista -más o menos amplia- de recomendaciones suplementarias que coordinen la satisfacción de las indigencias advertidas. Precisar las que se estiman circunstancias de necesidad o de carencia y enumerar los auxilios pertinentes forma parte de la trabajosa fabricación de las conclusiones relativas a esos contenidos variables.

$\mathrm{El}$ art. 83.1 LC ha dispuesto que, si así lo pide la administración concursal, el juez designe expertos independientes cuyo dictamen verse sobre la viabilidad de las acciones que, a juicio de aquel órgano, pueden ejercitarse para restituir a la masa activa del concurso los bienes y derechos que respaldan su integridad patrimonial. La prudencia legislativa ha entendido que estos actos de conservación requieren el apoyo de un consistente informe sobre el fundamento de las reclamaciones dirigidas a obtener la declaración judicial de su impecabilidad y procedencia. Sorprende que, debiendo primar el vigor de la iniciativa de la administración concursal que postula el asesoramiento independiente, gane firmeza, sin que se dé recurso alguno contra ella, la decisión judicial disuasoria del acceso a una asistencia técnico-jurídica que, de entrada, parece indispensable. Su sugerencia entraña un juicio sintético apriorístico, adaptado al núcleo intangible del derecho fundamental a un proceso con todas las garantías que ha introducido el art. 24.1 CE, pues autoriza a optar, previo asesoramiento, por deducir la pretensión de reintegro o abstenerse de hacerlo. La jurisdicción debe analizar la independencia de los expertos o señalar las cualidades necesarias para asignarles esa condición, proponiendo incluso otros remedios extrajudiciales que el art. 82.4 LC ha silenciado. El parecer emitido se incorpora a la relación aneja al inventario de los bienes y derechos que forman la masa activa del concurso. La injerencia de los expertos independientes conviene, una vez más, a los ejemplos de ilustración suplementaria que se van apuntando.

La regla del art. 99.1 LC incentiva la emisión de pareceres jurídicos previos que -incidiendo en las alternativas de la propuesta de convenio- aporten reflexiones de signo equitativo sobre la dosis de justicia material que, como mínimo, conviene al análisis de la situación. De su sagacidad y tino dependerá la suerte asignada por la persuasión intelectual del discurso a las respectivas elecciones -obra de los autores de la propuesta de convenio- o la medida en que se estime razonable ampliarlas, reducirlas o modificarlas. La desconcentración o subdivisión de las alternativas es fecunda si excita a reflexiones -de especial aprecio- que otorgan un predominio indiscutible a la más equitativa de las opciones presentadas. También puede ocurrir que, ante la fisonomía o las particularidades del concurso, un exceso de alternativas concurrentes obnubile la serenidad lógica de cuantos -alienados en una defensa numantina de las opciones propias- disminuyen o ciegan las oportunidades del razonamiento integrador de la equidad. 


\section{Supuestos aconsejables de intervención equitativa que pueden darse en momentos notables del proceso concursal}

Estos análisis técnico-jurídicos recomiendan la intervención equitativa de un tercero que media entre los autores y los destinatarios de las alternativas de la propuesta de convenio. Si se ofrecen contenidos de sana compatibilidad, la mediación capitalizará sus ventajas e inventará -en su acepción etimológica de descubrimiento o hallazgo, no de frívolo arbitrio para salir del paso- razones que, sumadas a las causantes de la coincidencia, justifican el precio a pagar por apartarse de actitudes secundarias o menores, cuyo sacrificio se compensa con el valor de la adhesión común a lo que unánimemente quiere conservarse. Si las alternativas son irreconciliables, el mediador-cuya imaginación tiene que conjugar la conciencia inerrante de la realidad con la intuición de soluciones coaceptables- formulará una propuesta de refundición y la someterá al parecer de cada uno de los grupos portadores de sendas propuestas autónomas y diferenciadas. El mediador ha de agotar, hasta la extenuación, la diligencia necesaria para lograr la síntesis de una propuesta unificada y útil o, al menos, ofrecer un compendio simplificado de propuestas convincentemente compatibles.

$\mathrm{El}$ art. 64 LC instituye competencias judiciales de excepción para que, luego de presentada la solicitud de declaración del concurso, se arbitren las prevenciones llevaderas a tutelar la viabilidad futura de la empresa y conservar una dosis de empleo consecuente con el estado de cosas objeto de análisis. Las medidas judiciales -que se interesan y decretan- son parte del aparato de gestión de la crisis que, en virtud de lo pedido, sufren las relaciones colectivas de trabajo y los contratos individuales dependientes de sus vicisitudes. Hay que adoptar, según los casos, medidas máximamente reductoras -consistentes en declarar la extinción colectiva de todos o parte de los contratos de trabajo- y medidas de proporciones medias, que abarcan las definitivas de modificación sustancial de esos contratos -cuyas obligaciones se novan en los términos del art. 41.1 I ET (Estatuto de los Trabajadores de 10 de marzo de 1980) - y las provisionales de suspensión que, andando el tiempo, revierten o abocan a soluciones extintivas. El período de consultas -que el art. 64.5 LC considera abierto tras recibirse la solicitud formuladaconcierne, en general, a la pertinencia de aquellas medidas y, en particular, a su repercusión en el empleo y en el porvenir viable de la empresa. No es de sencillo cumplimiento el deber de negociar de buena fe para convenir con arreglo al depósito del orden natural de la equidad y sanear la crudeza de las contiendas sindicales. Los escollos -jurídicos y económicos- de esta peripecia concursal requieren echar mano de la contribución mediadora que promueva y consiga un acuerdo sobre los extremos polémicos, con las limitaciones de orden público que los arts. 64.9 y 66 LC han dispuesto para los casos de modificación sustancial de las relaciones de trabajo o de las cláusulas de los convenios colectivos vigentes. La acertada judicialización del pro- 
cedimiento -afín al administrativo de regulación de empleo que establecen los arts. 47 y 51 ET- se inspira en criterios de conexión, celeridad y unidad de las verdades procesales. Son actividades mediadoras las que -a la par de las que operan en las negociaciones sindicales- tienden a asegurar los justos resultados del período de consultas y a eliminar los riesgos de fraude, coacción, dolo o abuso del derecho que, según el art. 64.7 LC, impiden aprobar el acuerdo afectado por algún vicio de la voluntad o por las conductas extralimitadas que reprueba el art. 7.2 C.c.

Además de aportar, con la diligencia exigible, sus dotes de intervención correctora o constructiva, los mediadores han de estar a las reglas de oro o pautas de metodología que gobiernan sus operaciones. He aquí algunas de ellas. El acceso a la negociación sindical, en que intervienen, requiere asumir actitudes subjetiva y objetivamente favorables a las soluciones de concesión y compromiso. Las concesiones tolerables dependen de las aptitudes de los negociadores, que el mediador debe conocer para obrar en consecuencia, de la relación de fuerzas que entre ellos existe y condiciona el posibilismo de sus iniciativas, de su capacidad o voluntad de administrar ese estado de cosas y de las variables -más o menos sensibles- ínsitas en lo accidentado de la coyuntura económica. El empleo -patente o soterrado- de procedimientos o actitudes desleales engendra una tirantez de relaciones que lamina la confianza indispensable para el progreso de la negociación. La negociación se estanca o se disuelve si, desde un principio, las partes no renuncian a observar comportamientos desleales y demuestran el sincero propósito de actuar, sin paliativos, en clave de flexibilidad y buen entendimiento. Aspecto álgido de la negociación es el de plantear una formulación inicial e intransigente de reivindicaciones extremas, con pocas probabilidades de aceptarse, o presentar peticiones templadas $\mathrm{y}$, a la larga, susceptibles de consolidarse y de prevalecer sustancialmente. Los acuerdos relativos a cuestiones interlocutorias adquieren una eficacia provisional y dependiente de las revocaciones o cambios de criterio que acontecen hasta el término de la negociación.

Las actitudes de los representantes de los trabajadores y las especialidades de la mediación que las completa, coinciden con las seguidamente expuestas -sobre el tratamiento supletorio del plan de liquidación del concurso- y se extienden a cuantas situaciones análogas exijan esa audiencia y aconsejen modos afines de composición. (V)

$\mathrm{El}$ art. 148.3 LC ha dispuesto que -además de las alegaciones necesarias para preservar el derecho a la defensa y el denominado interés del concurso- el plan de liquidación se someta a informe de los representantes de los trabajadores, cuyo interés colectivo se supedita al buen fin de las operaciones pendientes. Operaciones que -como vía natural de proteger el interés común de los titulares de los créditos- se agotan con la realización forzosa de los bienes y derechos englobados en la masa activa del procedimiento. Al preferirse la enajenación unitaria del conjunto de los establecimientos, 
explotaciones y demás unidades productivas de bienes y servicios del concursado, se erige una universalidad de bienes o grupo de emergencia que mantiene la indivisibilidad del objeto e impide fraccionar o dispersar los elementos de un patrimonio que así subsiste sin disminución de su valor. Para evitar la desigualación que proscribe el art. 9.2 CE, se regula un trámite de audiencia en que el dictamen de los representantes sindicales incluye observaciones o propone modificar los términos en que el plan de liquidación se ha trazado.

Estos dictámenes pueden contener sugerencias extensivas a otros casos en los que procede una intervención semejante de los representantes sindicales.

Cabe, en primer lugar, que la representación de los trabajadores rechace, frontalmente y sin más argumentos, el plan de liquidación del concurso. Esta actitud no se condice con la observancia de las cargas de colaboración -que los arts. 118 CE y 17.1 LOPJ imponen a cuantos asumen posiciones conexas con el objeto del proceso- y con la obligación central -recabada del sindicato clásico y de los representantes unitarios por el art. $7 \mathrm{CE}-$ de contribuir a la promoción y defensa de los intereses económicos y sociales que les son propios. La disconformidad ayuna de fundamento explícito -que se reduce a un no rotundo y categórico- sólo tiene sentido y debe interpretarse como silencio elocuente si, fuera de toda duda, constituye una manifestación de voluntad demoledoramente expresiva del mensaje que se quiere cursar. A saber, que el contexto del plan o algunos de sus ingredientes son notoriamente salvajes en vista de la convicción compartida por cuantos, verazmente informados sobre el particular, reaccionan conforme al dictamen de la recta razón que los juzga lesivos para los intereses de los trabajadores e irreconciliables con el contenido esencial o núcleo invulnerable de los derechos sociales amparados en los arts. 35.1 y $41 \mathrm{CE}$. No existe entonces una negativa injustificada o acromática, sino una declaración de voluntad tácita cuya vehemencia inconfundible suple a una argumentación sensata, coherente con las demandas sociales y presta a denunciar el desencanto causado por la planificación que se rehúsa.

Otra especie de reacción sindical, menos emocional y más cauta, disiente de la propuesta del plan de liquidación con un informe razonado, cuyo discurso - persuasivo y difícil de contravenir- denuncia la antijuricidad o la antisocialidad de sus cláusulas. Haciéndolo en términos -transparentes, inteligibles y rotundos- que revelan lo alarmante de la situación y el serio fundamento de la negativa a compartir dicho plan. Cualquier lector sensato comulga, sin esfuerzo, con las razones del rechazo y, restando a la propuesta todo su valor, la destituye de solvencia moral y jurídica. Sucede así porque su elaboración no asiente a las conclusiones mínimamente aceptables que, para suscribirla, le hagan decir algo distinto de la inutilidad que el dictamen sindical le reprocha, sin margen para relevarla ni ayudar a rehacer un texto planificador que ocupe su lugar. 
Cabe que, prefiriendo una actitud condicional, el parecer de los representantes sindicales subordine la acogida del plan de liquidación del concurso -cuyas líneas de fuerza sobreviven indemnes- a la adición de pormenores que, sin modificarlo esencialmente, contienen complementos aptos para consolidar la presuposición o base del negocio que funda los criterios de esa representación. Se apuntan precisiones, matices o aderezos que, respetando las orientaciones capitales del plan de liquidación, le enriquecen, aceleran su efectividad y garantizan lo ventajoso y útil del todo razonable en que se puede convertir. La básica bondad de la propuesta recibe componentes accidentales -relevantes para el interés colectivo de los trabajadores y, desde luego, irrenunciables- que, lejos de entorpecerla, se armonizan con sus aspiraciones y cooperan a perfeccionarla.

Cabe que el informe sindical -hostil a la aceptación condicional de la propuesta- la rechace alegando que las omisiones, excesos o defectos del plan de liquidación vulneran tan visiblemente el interés colectivo de los trabajadores, que sólo puede compartirse si se da entrada a la contrapropuesta consistente en ciertas modificaciones sustanciales. No se trata, como en el caso anterior, de añadir ingredientes accidentales a la sustancia inconmovible de la planificación sugerida, sino de alterarla y mudar su fisonomía con las novedades de un plan vicario del que es objeto de consulta.

La intransigencia o el tono radical de la postura de los representantes sindicales, en defensa del interés colectivo, se atempera equitativamente si -antes de expedirse el informe- la destreza de los oficios mediadores logra conformidades o consensos que acortan las distancias y suavizan las asperezas opuestas por esa representación. Se produce un parecer formalmente unilateral y anticipadamente convenido para que, al expirar el plazo de emisión, la administración concursal haya dado por buenas y hecho suyas las variaciones que -tras prosperar los buenos oficios de la mediación- van a integrarse en el informe pendiente de elaboración y recibo.

Puesto que las conductas sindicales se alimentan de respuestas emocionales, actitudes empíricas, improvisaciones y posiciones lógicas entremezcladas, de costosa sistematización y deslinde, son imaginables otras variantes de las posiciones que admite el informe prescrito en el art. 148.3 LC.

No es fácil evacuar, sin los auxilios adecuados, una respuesta solvente. El agotamiento equitativo del trámite del art. 148.3 LC reclama la mediación -modo de composición equidistante de la conciliación y el arbitraje- de expertos exteriores que se inmiscuyen en el seno de la representación sindical, donde las actitudes radicales no se cohonestan con las posturas moderadas de sus componentes, y viceversa, si no es gracias a lo eficiente de la interposición -tenaz y escrupulosa- de los agentes mediadores. Hay que proceder, dada la trascendencia del momento, a la pacificación interna del órgano y garantizar su propósito de emitir una respuesta satisfactoriamente constructiva para que, sin anticipar su significado y alcance de fondo, se eviten las disidencias insalvables y resurja -revitalizándole- el indispensable 
espíritu de cooperación. He ahí el debate democrático y cuerdo que se precisa para materializar conclusiones -coincidentes y sólidas- que paralicen las contrapropuestas suicidas o inviables. Esta mediación de acondicionamiento inicial caracteriza al estilo didáctico de los mediadores que, induciendo a la toma de decisiones racionalizadas, desbaratan cuantos prejuicios -gratuitos o inmovilistas- atenazan, a veces, el ejercicio de las funciones sindicales.

En la primera de las variantes de respuesta indicadas, huelga la mediación en cuanto al fondo si -según las instrucciones del propio mediador- lo ruidoso y enérgico de la negativa, aunque ayuna de motivación, bastan para señalar los orígenes y aclarar inequívocamente el alcance del silencio con el que se responde.

Si la negativa absoluta se funda en la antijuricidad o la antisocialidad de un plan de liquidación cuyo análisis no demuestra, sin más, uno u otro de tales defectos, entra en juego la labor de mediación o adoctrinamiento influyente que actúa sobre el órgano de representación sindical. El mediador ha de inculcar a los representantes de los trabajadores -que emocionalmente han dicho no a la planificación argüida- la verdad y la necesidad de todas y cada una de las objeciones que debe contener el informe para contrarrestarla. Hay que encontrarse en posesión de una notable aptitud persuasiva, porque no se trata de eliminar o reducir las contradicciones entre opuestos, sino de convertirlas -si existen- en afinidades y vigorizar la declaración de la voluntad colectiva cursada, sin fisuras y unitariamente, a la jurisdicción receptora de ese parecer. Ello exige, en razón de la calidad profesional del mediador como jurista, conciliar los datos extrajurídicos de su tesis -que componen el supuesto de hecho- con unos razonamientos de Derecho cuya solidez condiciona, además de la asimilación del informe, su impacto en la resolución judicial y en la suerte del recurso devolutivo que el art. 148.2 LC concede contra ella.

Lo expuesto se predica, guardadas las distancias, de situaciones semejantes. A saber, la producción de un informe que, para asentir a la propuesta de liquidación, se supedita al añadido de referencias o cláusulas accidentales, la sustitución de la propuesta por otra incompatible que se emite para desalojarla, la modificación renovadora de una toma de posición contradictoria y la mediación interlocutoria que adelanta transacciones o acuerdos incorporados luego al texto definitivo del informe.

\section{Otros casos de mediación cualificada en las operaciones del concurso}

El art. 100.2 II LC admite que la propuesta de convenio del concurso incluya propuestas de enajenación del conjunto de los bienes y derechos del concursado, afectos a su actividad empresarial o profesional, o de las unidades productivas concretas cuyo titular es una persona natural o jurídica. La 
audiencia de los representantes de los trabajadores -a la que convienen las consideraciones hechas antes sobre los arts. 148.3 y 149.1 regla $1 .^{a}$ II LCsirve para calibrar el ofrecimiento -que presupone la prosecución por el adquirente de la actividad específica de las unidades productivas a que se refiere- y valorar el plan de viabilidad que reseña los recursos hábiles, los medios y condiciones de obtenerlos y los compromisos de su prestación a cargo de terceros. Esta audiencia suscita los mismos problemas y provoca precisiones análogas a las que ya se han indicado.

Otro tanto cabe decir de la regulación que -para salvar las lagunas o la falta del plan de liquidación del concurso- dicta el art. 149.1 regla 1. ${ }^{a}$ II LC, si -decidiéndose la enajenación directa del todo de la empresa- queda desierta la subasta pública convocada al efecto o la jurisdicción resuelve enajenar todos o alguno de sus elementos componentes. La elección de los adquirentes -entre cuantos presentan las ofertas respectivas de comprarecaerá en los que más responsable y convincentemente garanticen la continuidad de la producción, la conservación de los puestos de trabajo y la satisfacción de los intereses de los acreedores. Al ejercicio de estas preferencias deben preceder las operaciones de tanteo, calificación y diagnóstico del mercado, la comprobación de la solvencia de las ofertas proferidas, el conocimiento de las oportunidades de su presentación, la determinación equitativa de los precios de la enajenación -para evitar la ruptura de la conmutatividad contractual- y cuantas más acrediten la excelencia de una mediación significada por la ilustración, la imaginación y el éxito de sus actuaciones. Mediación que, para aunar criterios y alejar perturbadoras discrepancias, registra dos fases. Interviene primero en el seno del órgano de representación sindi$\mathrm{cal}$, aminorando diferencias, practicando operaciones de coordinación y cooperando a la adopción de criterios unitarios de base. Participa después, con sensibilidad y detención, en las conversaciones previas a la conclusión del negocio jurídico de enajenación, combinando los criterios legales de adjudicación preferente con las iniciativas complementarias que aconsejan las particularidades del caso.

\section{Utilidad de las formas de mediación equitativa en los casos de 'enaje- nación forzosa del todo empresarial' o de unidades productivas autó- nomas}

La empresa es un acervo de bienes y derechos -de muy variada condición- que pueden ser, en su conjunto, objeto de tráfico jurídico. El art.149.2 LC dispone que, a efectos del régimen de las relaciones de trabajo, hay sucesión de empresa cuando -al enajenarse, como un todo o unidad fisonómicamente indisoluble, los bienes y derechos del concursado- perduran la entidad económica de esa aglutinación y la capacidad de proseguir la actividad -esencial o accesoria- que, desde sus orígenes, aplica los medios disponibles 
-personales y reales- al cumplimiento de los fines previstos. El fenómeno de la sucesión en la empresa, lejos de rehacerla artificiosamente, ofrece las ventajas de integrar los factores representados por el capital y demás recursos de inversión, la fuerza de trabajo dependiente o adscripción de los trabajadores por cuenta ajena, y la organización a cargo de un círculo rector que, con elasticidad variable, adopta decisiones coherentes y unitarias. Encaminadas, todas ellas, a acrecentar los beneficios económicos, mitigar la pulverización del empleo y proveer, de una parte, a las demandas del consumo privado y, de otra, al normal funcionamiento de los servicios esenciales de la comunidad. Gracias a una medida de apoyo y resonancia de la voluntad transformadora del art. 9.2 CE, el adquirente de esa universalidad se aprovecha de la reducción de las deudas asumidas por los organismos oficiales que alivian las cargas económicas de la empresa transmitida e invitan a esforzarse en pro de su continuidad.

Para facilitar esta última y defender el empleo, el cesionario, adquirente de la empresa, y los representantes de los trabajadores pueden suscribir acuerdos modificativos de las condiciones colectivas de trabajo. El art 149.2 LC desliza un tratamiento excepcional de las relaciones grupales de trabajo afectadas por la enajenación concursal y -como ámbito funcional adecuado a la morfología espontánea de las unidades sindicales de contratación- designa el de la empresa subsistente. Sorteados los escollos de la liquidación realizadora, la empresa sigue - proa adelante y en virtud de su presumible viabilidad- poniendo bienes y servicios en el mercado de libre competencia. Si la modificación de las condiciones colectivas de trabajo debe respetar la autonomía sindical, los oficios de la mediación han de integrar el compromiso y la libertad de acción para afianzar la equidad de los acuerdos que a la sazón se perfeccionan. La viabilidad futura de la empresa es la suficiencia para sobrevivir erguida -activa y firme- en el mercado, electrizar sus propósitos de presencia duradera y no efímera, y cumplir fielmente las funciones sociales que, de manera expresa o tácita, le incumben. El mantenimiento del empleo no se ha de confundir con la indemnidad o conservación total de su volumen, pues depende de las coyunturas y oportunidades que, atenuando siempre su degradación, toleran una recuperación acorde con las posibilidades y los requerimientos del concurso.

Esta especie de cuasiconvenios exige habilidades afines a las de la negociación de un convenio colectivo formal y precisa de un componente mediador sin el cual sus resultados nunca son los óptimos que cabe alcanzar.

La mediación no se ciñe a las relaciones de que se ha hecho mérito y se ingiere en otras que surgen de la insistencia y la práctica consuetudinarias. Allí donde la soberanía sindical ha impuesto el hábito -propio de las acciones de democracia directa y, como tal, irreversible- de que las asambleas ratifiquen los pareceres, informes o respuestas de los representantes de los trabajadores, se potencia la utilidad de los oficios mediadores para evitar las consecuencias negativas de una masificación visceral y conseguir, en lo posi- 
ble, una conformidad civilizada. Si el éxito no acompaña a la misión encomendada, prevalece una emocionalidad -insensata y deletérea- que, al rubricar ese fracaso, confunde el triunfo del fuero de la autonomía sindical con el exterminio de la ilusión depositada en los merecimientos y resultados de la equidad negociadora.

\section{Conclusiones acordes con los razonamientos que preceden}

Hay dos clases de acciones con que, amén de otras más imaginativas y no menos recomendables, la comunidad de juristas gestiona -mediante soluciones de Derecho y arbitrios de mediación equitativa- ciertas vicisitudes del concurso. Las asistencias técnicas usuales de los especialistas -que sirven a un proceso judicial de corte clásico y de modernidad indiscutida- llegan a requerir, no pocas veces, una división del trabajo inherente a la importancia de las especializaciones y a los valores de la interdisciplinariedad. Los fenómenos de esta magnitud reclaman -previsiblemente o con urgencia impredecible- el auxilio extraprocesal de dictámenes, pareceres, informes y asesoramientos en la rama del Derecho material que identifica la causa de pedir o en otras disciplinas conexas. La dignidad de la aplicación del Derecho se prestigia gracias al talante pluralista-comprensivo de la apertura intelectual a la verdad, de la coincidencia justificada en lo común y de la divergencia plausible en lo que se discrepa- y la sana libertad de la comunidad de juristas. Ahí reside el espíritu móvil y sensible de sus componentes y se confirman los aciertos del profetismo estructuralista que, superando la concepción del Derecho como un producto a secas del normativismo judicial, le adivina en la confluencia de cuantos acontecimientos y/o conductas -reflexivas o emocionales, directas o indirectas- desencadenan resultados equitativos y aptos para expulsar a la injusticia de los reductos en que se guarece para perpetuar sus agresiones.

El haz de soluciones que, gracias a la novedosa disciplina del concurso, postergan la conversión de bienes en dinero y prefieren dejar a salvo la unidad y la continuidad de las empresas, denota un sentimiento constitucional mejorado por las soluciones de equidad -en cuyo ciclo se ingieren-y por el refuerzo de las asistencias jurídicas externas que animan la expeditividad de la justicia. Esa política de supervivencia productiva se inspira en la equiparación de la equidad a la justicia material que el art. 1.1 CE ha elevado a valor superior del ordenamiento jurídico y situado en el vértice de su reproducción piramidal. Responde a la consigna de transformación que formula el art. 9.2 CE, porque aspira a hacer real y efectiva la libertad de empresa que, de otro modo, corre la más indeseable y desventurada de las suertes. Propicia el cumplimiento de la función social de los instrumentos y medios de producción que el art. 33.2 CE atrae al elenco común de sus finalidades. Coordina los inconvenientes de la crisis económica con la tutela de los con- 
tenidos intangibles de los derechos sociales sancionados en los arts. $35.1 \mathrm{y}$ $41 \mathrm{CE}$. Refuerza la tesis de que el art. $38 \mathrm{CE}$ acoge un derecho-función o derecho-bifronte que, además de perseguir y obtener el beneficio, obliga a dispensar ciertos servicios públicos, a prestar algunos servicios esenciales de la comunidad, sin cuyo regular funcionamiento la sociedad decae y se disloca, a ocuparse de los imperativos del consumo y a garantizar oportunidades de empleo acordes con la dignidad de la persona.

Esta reorientación procede del ascenso de la libertad de empresa, en un régimen de economía de mercado, a la condición de derecho subjetivo fundamental. El principio de primacía del Derecho Comunitario prohíbe que el ordenamiento constitucional -donde la libertad de empresa acampa bajo la rúbrica De los derechos y deberes de los ciudadanos (sec. 2. ${ }^{\mathrm{a}}$, cap. 2. ${ }^{\circ}$, tít. I $\mathrm{CE}$ - adjudique al Derecho concursal un tratamiento menos excelente que el conferido a las libertades básicas de establecimiento y circulación de capitales por los textos fundamentales u originarios del Derecho europeo y por la, no hace mucho, malogrado TCUE. (Tratado por el que se establece una Constitución para Europa, cuyo texto informativo data de la Conferencia de 24 de junio de 2004).

\section{Bibliografía de orientación}

ÁLVAREZ, I., «El futuro de la mediación preprocesal», La ley, 14 marzo 2007, pp. 14-16.

Álvarez, M. T., «La mediación en asuntos civiles y mercantiles», Revista del Poder Judicial, n. ${ }^{\circ}$ 77, pp. 243-304.

BARCEllona, P. et al., L'uso alternativo del diritto. Roma-Bari: Ed. Laterza, 3 vols., 1974.

Boldo, C., Levantamiento del velo y persona jurídica en el Derecho Privado español. Pamplona: Ed. Aranzadi, 1996.

Boulding, K., Conflict and defence: A general theory. Nueva York: Ed. Harper, 1962.

CAHN, E., The sense of injustice. Nueva York: Ed. New York University Press, 1949.

CANDElario, I., El convenio de continuación como medio de protección del crédito en los procedimientos concursales. Granada: Ed. Comares, 1999.

CASTÁN, J., «La formulación judicial del Derecho y el arbitrio de equidad», Revista General de Legislación y Jurisprudencia, pp. 219-272, Madrid: Ed. Reus, 1953.

Cordón, F., Comentarios a la Ley Concursal. Cizur Menor (Navarra): Ed. Aranzadi, 2004.

DEJEAN DE LA BATIE, N., Appreciation in abstracto et appreciation in concreto en droit civil francais. París: Ed. Librairie Generale de Droit et de la Jurisprudence, 1965. 
Dessens, J., Essai sur la notion d'equité. Toulouse: tesis inédita, 1934.

Fernández-Ballesteros, M. A., Derecho concursal práctico. Madrid: Ed. Iurgium, 2004.

Fisher, R. y URY, W., Getting to «yes». Nueva York: Ed. Penguin Books, 1987.

Gómez MarTín, F., Administración concursal. Valencia: Ed. CISS, 2004.

GonzÁlez BilbaO, E., et al. Nuevo Derecho concursal. Bilbao: Ed. Gómez Martín y Fernández Bilbao, 2004.

HEIDER, F., The psichology of interpersonal relations. Nueva York: Ed. John and Sons, 1958.

Hernández Gil, A., Metodología del Derecho. Madrid: Ed. Antonio Hernández Gil, 3 vols., 1971-1976.

HerrerA, E., Manual de la Reforma concursal. Madrid: Ed. Europea de Derecho, 2004.

JiMÉNEZ C., La nueva legislación concursal. Madrid: Ed. Instituto de empresa, 2004.

JiMÉNEZ De Asua, L., «La culpabilidad», Tratado de Derecho Penal. Buenos Aires: Ed. Losada, 1956.

LorCa J. et al., La nueva Ley Concursal. Donostia/San Sebastián: Ed. Instituto Vasco de Derecho Procesal, 2004.

Molina, C., Persona jurídica y disciplina de los grupos sociales. Bolonia: Ed. Studia Albornotiana, 1995.

OlivenCIA, M., «El Derecho concursal: modernas orientaciones y perspectivas de reforma», La reforma de la legislación mercantil, Madrid: Ed. Civitas, 1979, pp. 315-352.

Prendes, P. et al., Guía Práctica Concursal. Cizur Menor (Navarra): Ed. Aranzadi, 2005.

PERELMAn, Ch., Les notions a contenu variable en droit. Bruselas: Ed. Bruylant, 1984.

Rojo, A., El convenio anticipado. Madrid: Ed. Civitas, 2004.

Sagrera, J. M. et al., Comentarios a la Ley Concursal. Barcelona: Ed. Bosch, 2004.

VELÁZQuez, M. A., Guía para una aproximación a la legislación concursal. Madrid: Ed. Dykinson, 2003.

Walton, R. et al., A behavioral theory of labor negotiations. Nueva York: Ed. Mac Graw-Hill, 1985.

Wildner, H., Die technik der Diplomatie: L'art de negocier. Viena: Ed. Springer, 1959.

Zorrilla, M. M., Teoría General del Derecho. Madrid: Ed. Dykynson, 2002;

— «Del sometimiento al imperio de la Ley, a la modernidad del arbitraje», Estudios de Deusto, vol. 55/2, 2007, pp. 185-211. 